\title{
Reforms woo scientists from mainland China
}

David Cyranoski, Tokyo

Taiwan is taking several tentative steps to open doors to researchers from the People's Republic of China and overcome half a century of scientific estrangement between the two.

The latest move to improve scientific relations came last week when Taiwan increased the maximum time that visiting researchers from the mainland can stay on the island from two years to three.

Other changes expected in the near future include the introduction of multiple-entry visas for visitors and new provision for the direct transfer of money to banks on the mainland, says Kuan-Hsiu Hsiao, an official at Taiwan's National Science Council.

Researchers say that multiple-entry visas are essential to encourage scientific exchange. Currently, visitors from the mainland must go through a laborious process, taking several months, to obtain a limited travel permit for Taiwan. But the permit does not allow travel outside Taiwan - to visit international conferences or laboratories abroad - greatly restricting the mobility of those mainland researchers who do spend time on the island.

There are fewer restrictions for researchers wishing to move in the other direction, although few Taiwanese go to the mainland to do research. But there is an increasing desire to develop collaborations as many Taiwanese note great improvements in scientific practices on the mainland. "When I visited five years ago, they just wanted to show build-

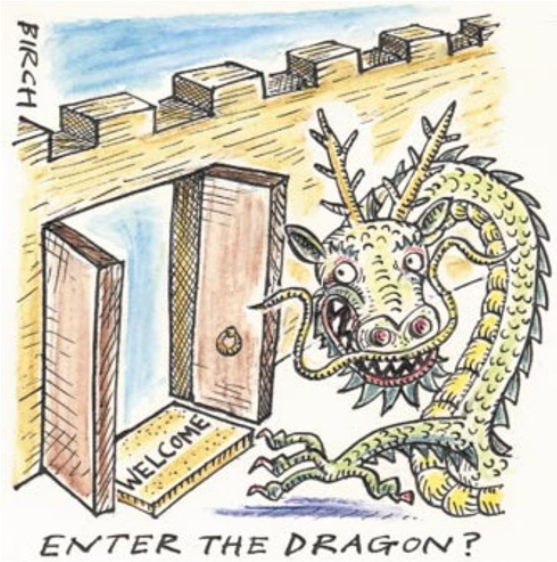

ings and machines. Now they want to discuss scientific methods and results," says one researcher with the Academia Sinica, Taiwan's premier research organization.

Some of the restrictions are relatively minor: rules against depositing money into mainland banks, for example, just mean that visiting researchers have to find a Taiwanese friend to make the transfer.

Nonetheless, the latest changes, in combination with others made late last year, will produce a more agreeable atmosphere for scientific exchange, researchers say. Last December, Taiwan implemented a reform to allow mainland-born spouses of Taiwanese nationals to work at universities and public research institutes. Previously, they needed two years of residency in Taiwan and eight years of residency outside mainland China to qualify.
And for the first time, mainland researchers working in Taiwan for more than four months will become eligible for Taiwan's national insurance, with the Academia Sinica required to ensure insurance coverage for mainlanders. This change is a response to an incident in which a visiting postdoctoral student amassed huge medical bills after being hit by a drunk driver and spending three months in hospital in a coma.

But a bottleneck remains for those seeking permanent positions. "Undefined restrictions leave no pathway for mainlanders to find a job in Taiwan except in very special cases," says an Academia Sinica researcher. Taiwan, for example, still does not recognize degrees from mainland universities when considering people for institute and university research positions.

The mainland also imposes some obstacles. Travel permits for researchers are often granted for only six months or one year barely enough time to get started on a research project.

According to a mainlander at one Academia Sinica institute, there are many reasons researchers from mainland China might want to go to Taiwan, including higher salaries, better facilities and a more international research environment. Taiwanese institutes and universities also face a dearth of qualified personnel and have a hard time attracting people from abroad because of language and cultural barriers. "If we make it easy, gradually [mainland researchers] will come," says Kuan-Hsiu Hsiao.

\section{France and Spain join forces over synchrotron project}

Xavier Bosch, Barcelona

Spain has agreed to help build a new synchrotron which is being planned outside Paris, in exchange for French participation in an as-yet unspecified major Spanish research facility.

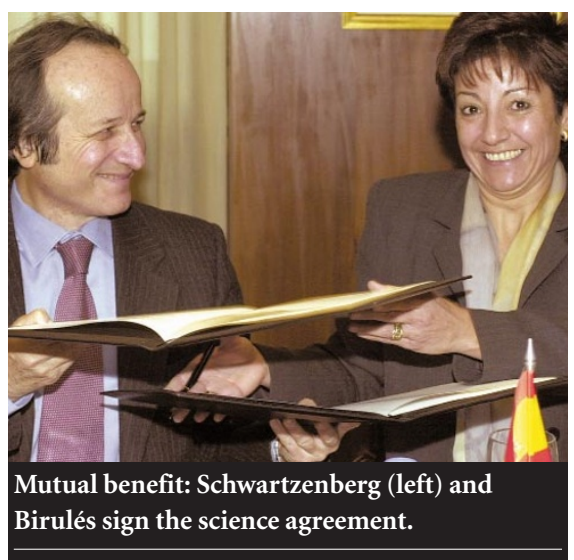

The Spanish and French science ministers, Anna Birulés and Roger-Gérard Schwartzenberg, reached an agreement in Madrid on 5 February to cooperate on the construction and operation of large research facilities. While Spain helps to build the Soleil synchrotron, it will consider various projects for French participation.

Neither country has disclosed the size of the Spanish contribution to the synchrotron, but a French newspaper has estimated it at FFr170 million (US\$24 million) towards a total cost of about $\$ 220$ million. Schwartzenberg told a press conference that Spanish researchers would join the scientific advisory board of the Soleil synchrotron.

Candidates for the Spanish facility, meanwhile, include a research vessel, a 10-metre optical telescope in the Canary Islands, and another synchrotron.

Spain appointed a committee last month

^ ๑ 2001 Macmillan Magazines Ltd to study the feasibility of building its own synchrotron, and is expected to decide whether or not to go ahead with the project by the summer.

Two years ago, a design study for a synchrotron facility to be housed at the Autonomous University of Barcelona was positively evaluated and its construction recommended by the European Science Foundation (see Nature 405, 604; 2000).

Jérémie Boussand, the science attaché at the French Embassy in Madrid, says that if Spain decides to proceed with the synchrotron, then that will be the project that France will support.

Synchrotron light sources, which enable researchers to closely examine threedimensional structures, have emerged in recent years as an important tool in materials science, chemistry, condensedmatter physics and structural biology. http://www.lls.ifae.es

NATURE |VOL 409 15 FEBRUARY 2001 | www.nature.com 